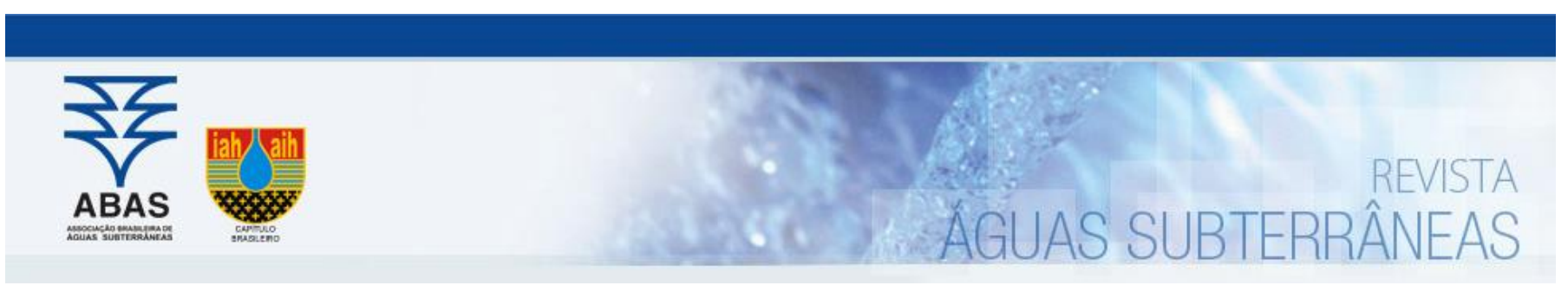

Estudos de Caso e Notas Técnicas

\title{
Avaliação Hidroquímica e de Parâmetros Físico-Químicos de Qualidade das Águas Subterrâneas da Zona Urbana do Município de Sousa-PB
}

\author{
Hydrochemical and Physical-Chemical Parameters of Quality Evaluation of \\ Groundwater in the Urban Zone of the Municipality of Sousa-PB
}

\author{
Mirelly Alexandre Gomes ${ }^{1}$; Emanuel Victor da Silva Ramos ${ }^{1}$; Luís Carlos dos Santos ${ }^{1}$; Samuel Guedes Bitu ${ }^{1}$; Antonio José Ferreira \\ Gadelha $^{1 凶}$
}

${ }^{1}$ Instituto Federal de Educação Ciência e Tecnologia da Paraíba - Campus Sousa, Sousa, PB

\gomesmirelly24@gmail.com, emanuelvramos@hotmail.com, luiscarlosenergisa@gmail.com, samuel.bitu@ifpb.edu.br, antonio.gadelha@ifpb.edu.br

\begin{tabular}{ll} 
& Resumo \\
\cline { 2 - 2 } Palavras-chave: & O semiárido do nordeste brasileiro tem sido castigado durante os últimos anos com uma estiagem prolongada caracterizada por \\
& precipitações irregulares e abaixo da média histórica para a região. Isso tem levado as populações a buscarem novas fontes de \\
Hidroquímica. & água para suprir suas necessidades. Uma das fontes mais procuradas são as águas subterrâneas. Foi o caso do município de \\
Qualidade. & Sousa no estado da Paraíba, que, por meio da prefeitura, promoveu a perfuração de diversos poços na zona urbana da cidade. \\
Águas subterrâneas. & No entanto, não foram feitos estudos hidroquímicos sobre a qualidade dessas águas. Neste sentido, este trabalho objetivou \\
Salinidade. & avaliar hidroquimicamente as águas subterrâneas de 13 poços da zona urbana do município de Sousa-PB no período de julho a \\
& dezembro de 2017. Foram avaliados os parâmetros pH, condutividade elétrica, carbonatos, bicarbonatos, cloretos, cálcio, mag- \\
& nésio, potássio e sódio. Verificou-se que as águas desses poços apresentam elevados teores de sólidos dissolvidos, tendo sido \\
& classificadas como sódico cloretadas e sódico bicarbonatadas. Com relação a um possível uso na agricultura, todas as amostras \\
& apresentaram um risco de salinização alto ou muito alto e um risco de sódio variando entre baixo e muito forte.
\end{tabular}

\begin{tabular}{ll} 
Keywords & Abstract \\
\cline { 2 - 3 } & The semi-arid region of the Brazilian northeastern has been grieved during the last years by prolonged drought characterized by \\
Hydrochemistry. & irregular precipitations and below the historical average for the region. This has led populations to seek new sources of water to \\
Quality. & meet their needs. One of the most sought sources is groundwater. This was the case of the municipality of Sousa in the state of \\
Groundwater. & Paraíba, which, through the City Hall, promoted the drilling of several wells in the urban area of the city. However, no hydrochemical \\
Salinity. & studies were done on the quality of these waters. In this sense, the objective of this work was to evaluate hydrochemically the \\
& groundwater of 13 wells in the urban area of the municipality of Sousa-PB from July to December 2017. The parameters pH, \\
Revisado por pares. & electrical conductivity, carbonates, bicarbonates, chlorides, calcium, magnesium, potassium, and sodium. It was verified that the \\
Recebido em: $18 / 03 / 2018$. & waters of these wells have high dissolved solids contents, having been classified as sodium chlorinated and sodium bicarbonated. \\
Aprovado em: $31 / 03 / 2018$. & Regarding a possible use in agriculture, all the samples presented a risk of high or very high salinization and a risk of sodium \\
ranging from low to very strong.
\end{tabular}

DOI: http://dx.doi.org/10.14295/ras.v32i2.29115

\section{INTRODUÇÃO}

Dada sua importância, o acesso à água de qualidade pode comprometer o desenvolvimento socioeconômico de determinada região e até a subsistência das comunidades afetadas pela escassez deste recurso. O semiárido brasileiro, no qual está incluído o sertão da Paraíba, sofre periodicamente com estações cíclicas de baixa precipitação pluviométrica, caracterizadas pela irregularidade das chuvas e pela falta de recarga significativa dos principais corpos hídricos dessa região. Isso leva as populações dessas áreas a buscarem fontes alternativas de água em períodos de baixa disponibilidade hídrica. Esse fato pode representar um risco à saúde dos indivíduos expostos a essas condições a partir do consumo de água de má qualidade.

De acordo com Cirilo (2008), o semiárido nordestino é uma região pobre em volume de escoamento superficial de água dos rios, situação explicada em função da variabilidade temporal das precipitações pluviométricas e das características geológicas dominantes, onde há a predominância de solos pouco espessos, dispostos sobre 
rochas cristalinas e, consequentemente, baixas trocas de água entre o rio e o solo adjacente. Esse fato explica a baixa disponibilidade de água nessa região, o que acaba forçando essas populações a buscar no subsolo uma fonte alternativa de água.

Segundo Costa et al., (2012), a água subterrânea tem potencial capacidade de transmissão de doenças causadas por microrganismos patogênicos provenientes de fezes de humanos e animais, ou por meio de substâncias químicas em concentração fora dos padrões permitidos pela Portaria 2914/11 MS. Por isso, torna-se indispensável a verificação e o acompanhamento de sua potabilidade.

Nas áreas urbanas expostas a um crescimento demográfico recente, as águas superficiais e subterrâneas estão propensas a sofrer alterações em suas características físicas, químicas e biológicas, devido ao aporte de substâncias oriundas de atividades antrópicas, o que ocasiona a contaminação e a salinização dessas águas. De acordo com Zavoudakis et al., (2007), no que diz respeito às águas subterrâneas, o aquífero livre é o que se encontra mais susceptível às contaminações, devido à sua exposição direta às possíveis fontes contaminantes.

Geralmente, as águas subterrâneas estão susceptíveis a apresentarem elevados teores de salinidade do que as águas superficiais. Segundo Zavoudakis et al., (2007), a salinidade nos meios porosos advém, principalmente, da constituição mineralógica dos meios litológicos percolados, do tempo de residência das águas, da interação com águas salinas, como com a cunha salina em aquíferos litorâneos, das águas residuárias magmáticas e de interferências externas, como as antrópicas.

Conforme relata Deustch (1997), os elementos considerados importantes e suficientes pela hidrogeoquímica para o estudo dos processos químicos na maioria dos aquíferos e suas relações com os sistemas hidrogeológicos são os constituintes principais $\left(\mathrm{Na}^{+}, \mathrm{K}^{+}, \mathrm{Ca}^{2+}\right.$, $\mathrm{Mg}^{2+}, \mathrm{Cl}^{-}, \mathrm{SO}_{4}^{-2}, \mathrm{HCO}_{3}^{-}$e $\left.\mathrm{CO}_{3}{ }^{2-}\right)$, por serem quase sempre e, majoritariamente, presentes nas águas subterrâneas.

Neste sentido, este trabalho tem como objetivo avaliar, a partir da classificação hidroquímica e parâmetros físico-químicos, a qualidade da água de poços subterrâneos da zona urbana do município de Sousa, localizado no sertão da Paraíba.

\section{CARACTERIZAÇÃO DA ÁREA DE ESTUDO}

O município de Sousa fica localizado na mesorregião do sertão do estado da Paraíba, distante 438 km da capital, João Pessoa. De acordo com o Instituto Brasileiro de Geografia e Estatística (IBGE, 2010) o município de Sousa apresentou no último censo, 65.803 habitantes, dos quais 51.881 moram na zona urbana do município.
O município é cortado pelos Rios do Peixe e Piranhas, dos quais apenas o Rio do Peixe atravessa a área urbana desse município. De acordo com a Embrapa Solos (Recife), o solo dessa área pode ser classificado como vertissolo, que caracteriza-se por ser um solo mineral não-hidromórfico, com séria restrição temporária à percolação de água. O clima sousense é tropical semiárido (do tipo Aw na classificação climática de Köppen-Geiger), com temperatura média anual é de $26,7{ }^{\circ} \mathrm{C}$ e precipitação média de 872 milímetros $(\mathrm{mm})$ anuais, concentrados entre janeiro e abril, sendo março o mês de maior precipitação (227 mm) (CLIMATE-DATA.ORG, 2018)

\section{MATERIAIS E MÉTODOS}

Foram selecionados 13 poços distribuídos em diferentes bairros na zona urbana do município (Figura 1), sendo que, ao lado de cada poço, a prefeitura alocou uma caixa d'água com 5.000 ou 10.000 litros de capacidade para disponibilizar a água para a população (Tabela 1). As amostras foram coletadas sempre no mesmo horário, iniciando-se às 07:00 horas, em garrafas plásticas de $500 \mathrm{~mL}$, devidamente lavadas, e transportadas em caixas térmicas para o Laboratório de Química da Unidade Sede do Campus Sousa do Instituto Federal de Educação, Ciência e Tecnologia da Paraíba (IFPB), onde foram realizadas as análises físico-químicas, de acordo com a metodologia descrita no Standard Methods for the Examination of Water and Wastewater (AMERICAN PUBLIC HEALTH ASSOCIATION APHA, 2012). Os parâmetros analisados, em duplicata, foram $\mathrm{pH}$, condutividade elétrica (CE), sólidos totais dissolvidos (STD), alcalinidade total, carbonatos, bicarbonatos, cloretos, dureza total, cálcio, magnésio, potássio e sódio. As coletas foram realizadas entre os meses de julho (início da estação seca) e dezembro (fim da estação seca) de 2017.

Os dados são apresentados na forma de Boxplots, gerados a partir do software Statistica 6.0, em que o ponto central indica a média dos valores obtidos, a caixa (box) indica os valores da média \pm 0 desvio padrão e, as linhas indicam os valores mínimo e máximo obtidos para cada parâmetro. São mostrados ainda os gráficos de correlação entre os parâmetros STD x Na e pH x $\mathrm{CO}_{3}{ }^{2-}$.

Com relação à classificação hidroquímica das águas, utilizou-se o Diagrama de Piper (1944), e para classificação quanto ao risco de salinização do solo, utilizou-se o diagrama proposto pelo Laboratório de Salinidade dos Estados Unidos - USSL (Richards, 1954), que se apresenta na forma de um diagrama semilogarítmico, no qual, com os valores de CE e da Razão de Adsorção de Sódio (RAS), mediante a combinação de letras e números, se estabelece o risco de salinização e de sodificação dessa água. Em ambas as classificações, fez-se o uso do software Qualigraf, desenvolvido pela FUNCEME (Fundação Cearense de Meteorologia e Recursos Hídricos). 
Figura 1 - Mapa de localização dos poços amostrados.

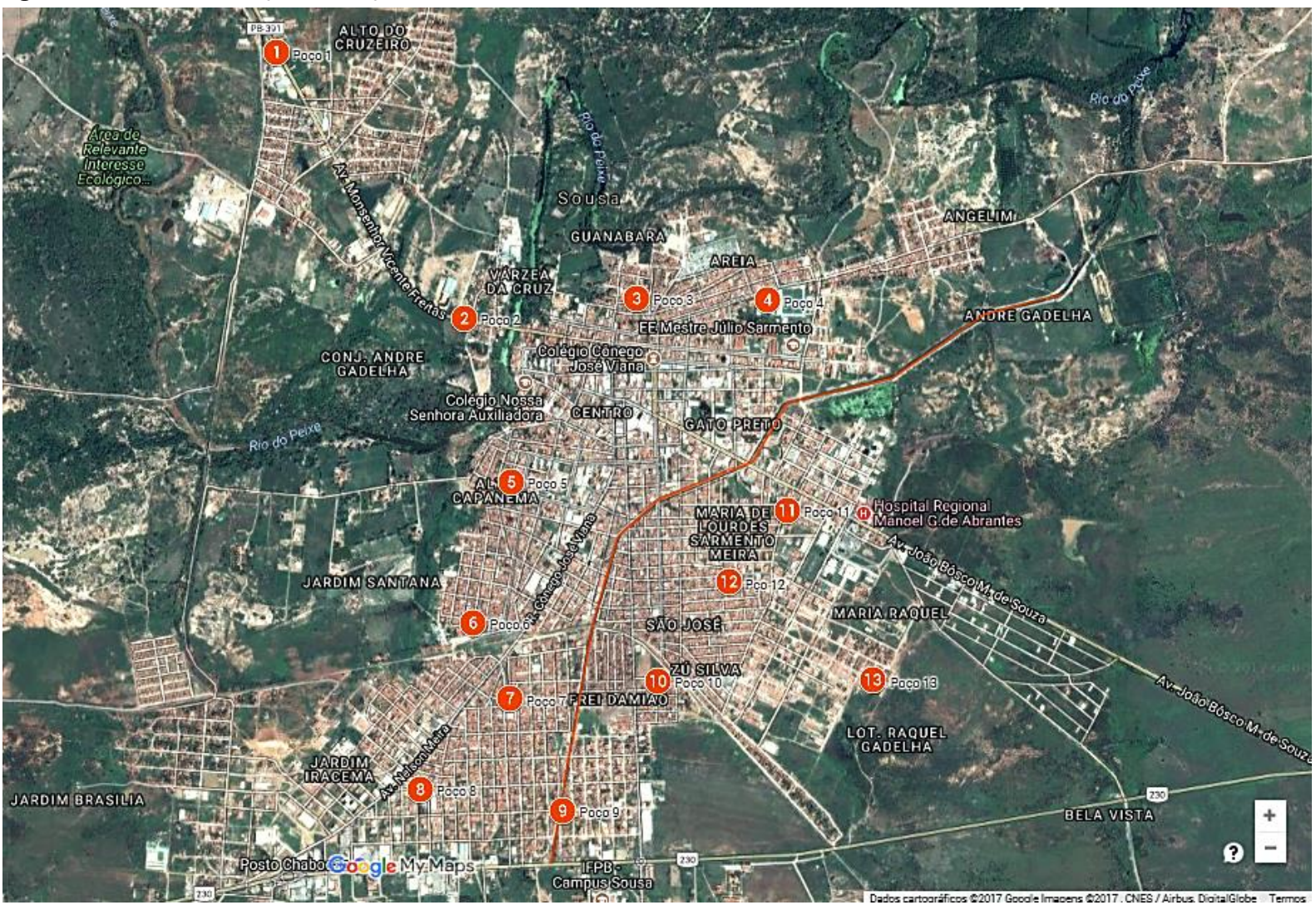

Tabela 1 - Características e localização dos poços amostrados.

\begin{tabular}{|c|c|c|c|c|c|}
\hline Poço & $\begin{array}{c}\text { Data de Perfura- } \\
\text { ção }\end{array}$ & Profundidade (m) & $\begin{array}{c}\text { Vazão } \\
(\mathrm{l} / \mathrm{h})\end{array}$ & Localidade & Localização \\
\hline 01 & $09 / 06 / 2015$ & 51 & 1500 & Alto do Cruzeiro & $\begin{array}{l}-6.74605 \\
-38.24398\end{array}$ \\
\hline 02 & $28 / 05 / 2015$ & 50 & 600 & Várzea da Cruz (PSF) & $\begin{array}{l}-6.75668 \\
-38.23644\end{array}$ \\
\hline 03 & 24/05/2015 & 51 & 2000 & Guanabara (PSF) & $\begin{array}{l}-6.75585 \\
-38.2295\end{array}$ \\
\hline 04 & $25 / 05 / 2015$ & 51 & 1800 & Estádio Marizão & $\begin{array}{l}-6.75594 \\
-38.22425\end{array}$ \\
\hline 05 & $20 / 07 / 2015$ & 41 & 5538 & Alto Capanema & $\begin{array}{c}-6.7632 \\
-38.23455\end{array}$ \\
\hline 06 & 08/08/2015 & 49 & 10000 & Jardim Santana & $\begin{array}{l}-6.76883 \\
-38.23607\end{array}$ \\
\hline 07 & 27/05/2015 & 50 & 600 & Estação (PSF) & $\begin{array}{l}-6.77187, \\
-38.23461\end{array}$ \\
\hline 08 & 24/07/2015 & 40 & 3130 & $\begin{array}{l}\text { Jardim Bela Vista (Vare- } \\
\text { jão) }\end{array}$ & $\begin{array}{l}-6.77547,- \\
38.23821\end{array}$ \\
\hline 09 & 23/06/2015 & 51 & 1142 & Jardim Sorrilândia II & $\begin{array}{l}-6.77631 \\
-38.23246\end{array}$ \\
\hline 10 & $18 / 08 / 2015$ & 50 & 2300 & Casas Populares (CSU) & $\begin{array}{l}-6.77116 \\
-38.22865\end{array}$ \\
\hline 11 & $20 / 07 / 2015$ & 51 & 1400 & $\begin{array}{l}\text { Condomínio Doca Ga- } \\
\text { delha }\end{array}$ & $\begin{array}{l}-6.76434, \\
-38.22344\end{array}$ \\
\hline 12 & $19 / 06 / 2015$ & 51 & 700 & Conjunto Dr. Zezé & $\begin{array}{l}-6.76718 \\
-38.22581\end{array}$ \\
\hline 13 & 06/06/2015 & 51 & 5200 & Alto do DNOCS & $\begin{array}{c}-6.7711 \\
-38.21999\end{array}$ \\
\hline
\end{tabular}

\section{RESULTADOS E DISCUSSÃO}

As Figuras 2, 3 e 4 apresentam os resultados obtidos para os parâmetros de alcalinidade total, bicarbonatos e carbonatos, respectivamente. Sabe-se que a alcalinidade total de uma água é causada pela presença de íons $\mathrm{OH}-, \mathrm{CO}_{3}{ }^{2-}$ e $\mathrm{HCO}_{3}$, e está relacionada à capacidade tamponante dessa água quanto à adição de ácidos. Em altas concentrações, pode provocar gosto ruim na água e efeito laxativo (VON SPERLING, 2005). O Padrão de Potabilidade no Brasil, estabelecido pela Portaria 2.914/2011 do Ministério da Saúde, limita o valor máximo em $500 \mathrm{mg}$ de $\mathrm{CaCO}_{3} / \mathrm{L}$ para este parâmetro. A partir da análise das Figuras 2, 3 e 4, verifica-se que 
o principal íon causador da alcalinidade nesses poços é o bicarbonato, presente em concentrações muito elevadas, em contraste ao carbonato, fazendo com que alguns desses poços ultrapassem o valor estabelecido pelo padrão de potabilidade.

Figura 2 - Boxplot para Alcalinidade Total (mg de $\mathrm{CaCO}_{3} / \mathrm{L}$ )

Box Plot Alcalinidade Total

Mean; Box: Mean \pm SE; Whisker: Min-Max

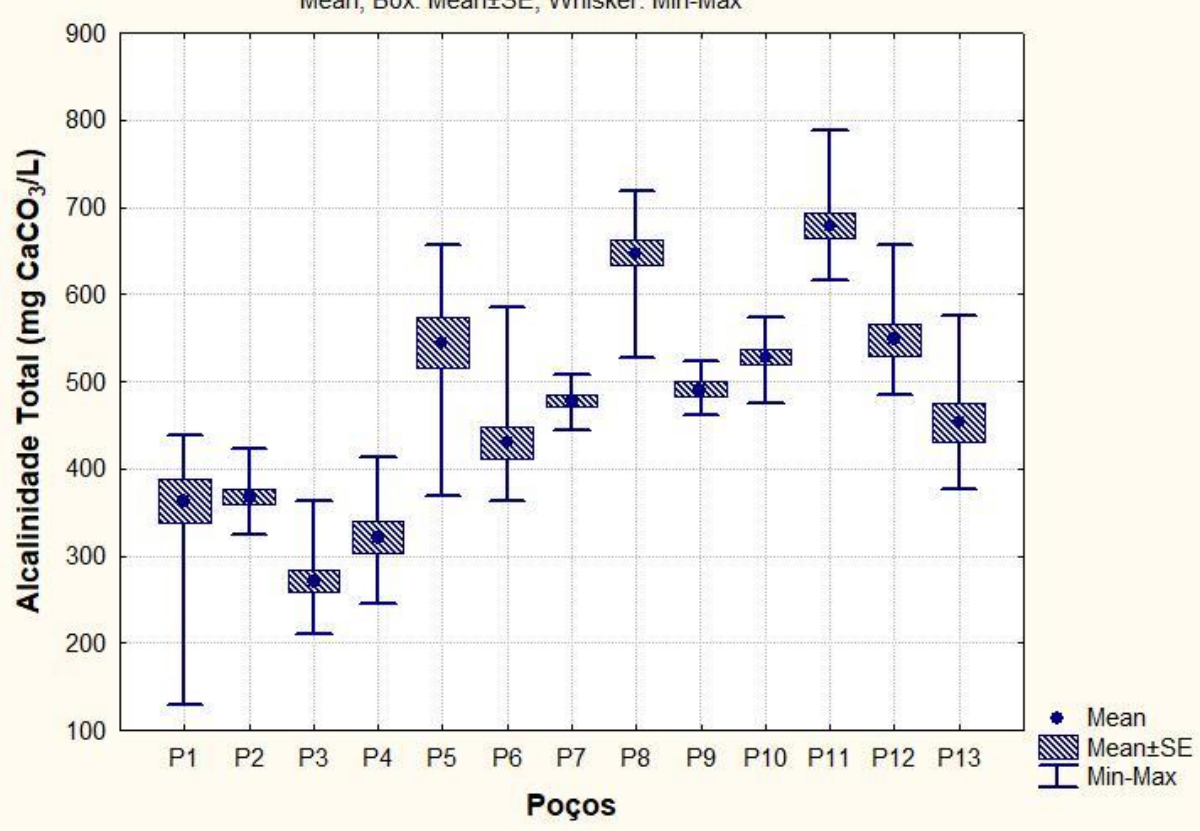

Figura 3 - Boxplot para Bicarbonatos ( $\mathrm{mg} / \mathrm{L})$

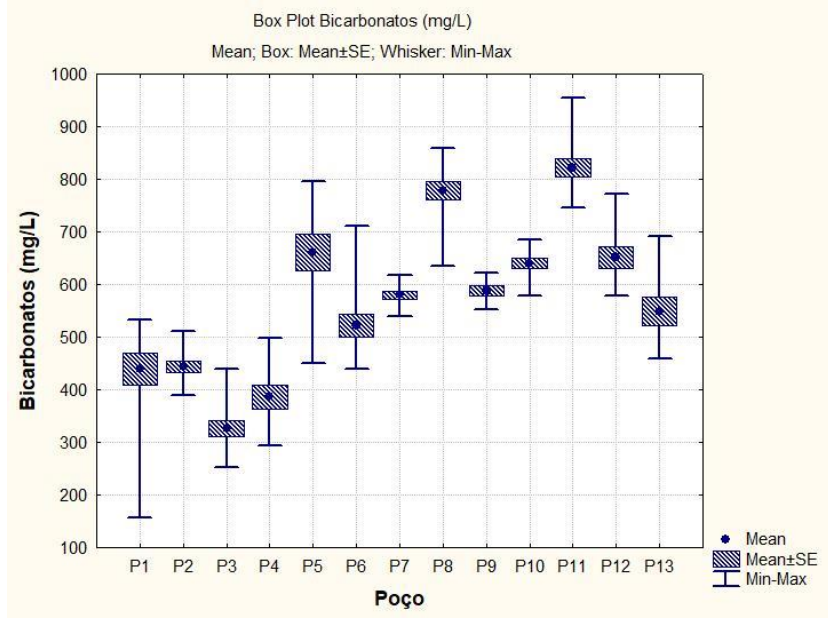

$\mathrm{O} \mathrm{pH}$ também está relacionado aos valores de alcalinidade, visto que, a concentração de íons $\mathrm{CO}_{3}{ }^{2-}$ e $\mathrm{HCO}_{3}$ - interferem na atividade do ín $\mathrm{H}^{+}$(VON SPERLING, 2005). Os valores de $\mathrm{pH}$ das amostras (Figura 5) ficaram um pouco acima de 7,0 e abaixo de 9,0 em todos os poços, situando-se dentro da faixa determinada pela Portaria MS
Figura 4 - Boxplot para Carbonatos ( $\mathrm{mg} / \mathrm{L}$ )

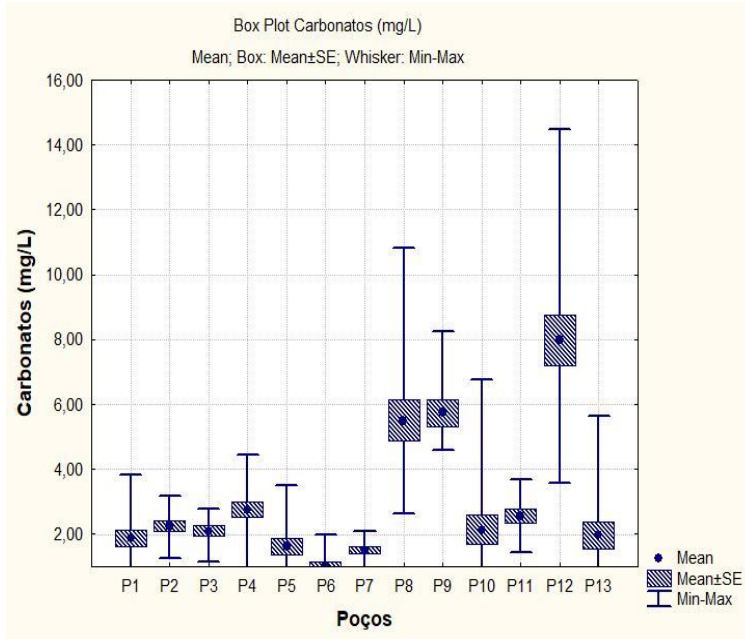

2.914. O fato do pH está na faixa básica é explicado pela elevada concentração de íons causadores de alcalinidade, estando intimamente ligado ao íon carbonato, conforme é mostrado na Figura 6, que apresenta a correlação entre esses dois parâmetros. 
Figura 5 - Boxplot para valores de $\mathrm{pH}$

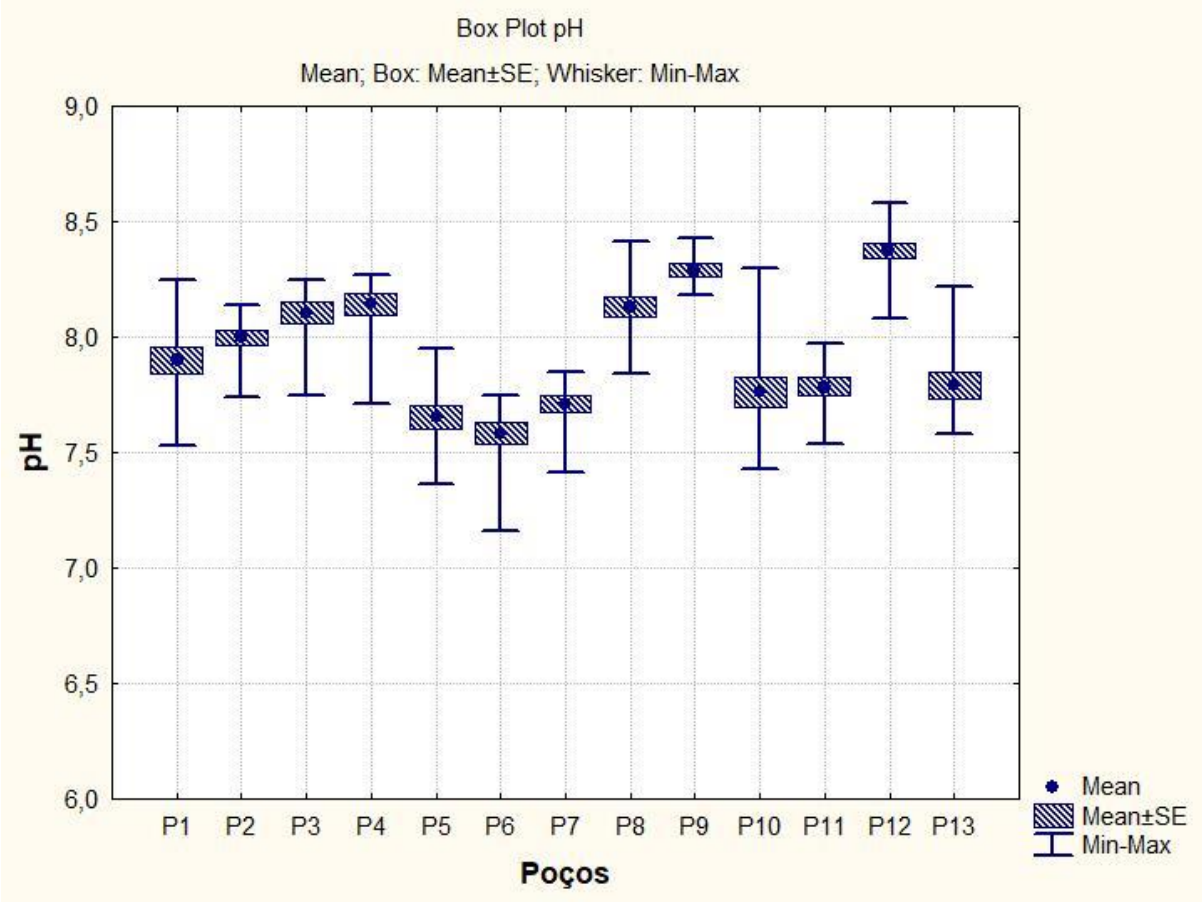

Figura 6 - Gráfico de correlação entre os parâmetros $\mathrm{pH} \times \mathrm{CO}_{3}{ }^{2}$

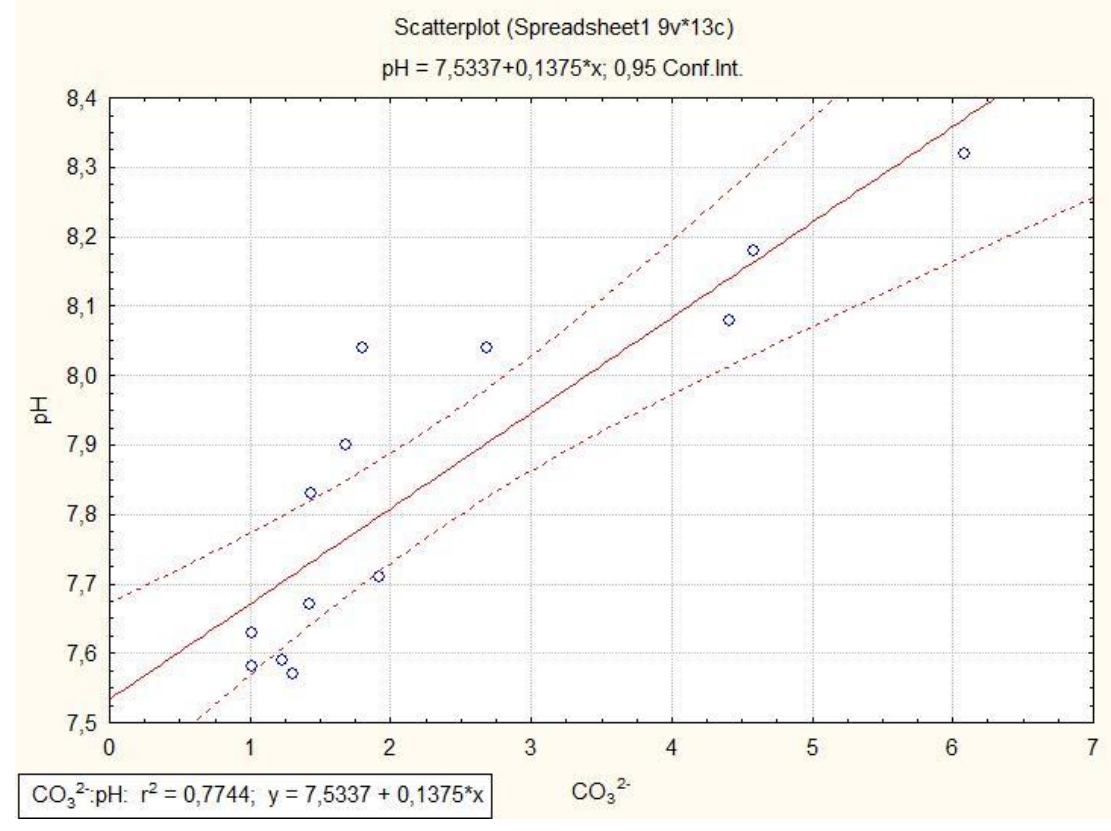

Outro parâmetro que aparece no padrão de potabilidade é a dureza total, que pode ser definida como a soma da concentração de cátions multivalentes na amostra (CANADÁ, 1979). Os resultados obtidos para dureza total, expressa em termos de $\mathrm{mg} \mathrm{CaCO}_{3} / \mathrm{L}$, estão apresentados na Figura 7. Verifica-se que todos os poços se enquadram dentro do limite estabelecido pela Portaria MS 2.914, que é de, no máximo, $500 \mathrm{mg} \mathrm{CaCO} / \mathrm{L}$. Valores elevados de dureza geram repulsa dos consumidores em função do gosto ruim provocado, além de ser responsável por incrustações em tubulações.
A dureza é causada principalmente pela presença de íons $\mathrm{Ca}^{2+} \mathrm{e}$ $\mathrm{Mg}^{2+}$, que têm seus resultados mostrados na Figuras 8 e 9. Verificase que o cálcio aparece em concentrações maiores que o magnésio em praticamente todos os poços, sendo, portanto, o principal responsável pela dureza das amostras. A legislação não estabelece valores limites para estes íons. 
Figura 7 - Boxplot para valores de Dureza Total $\left(\mathrm{mg} \mathrm{CaCO}_{3} / \mathrm{L}\right)$

Box Plot Dureza Total

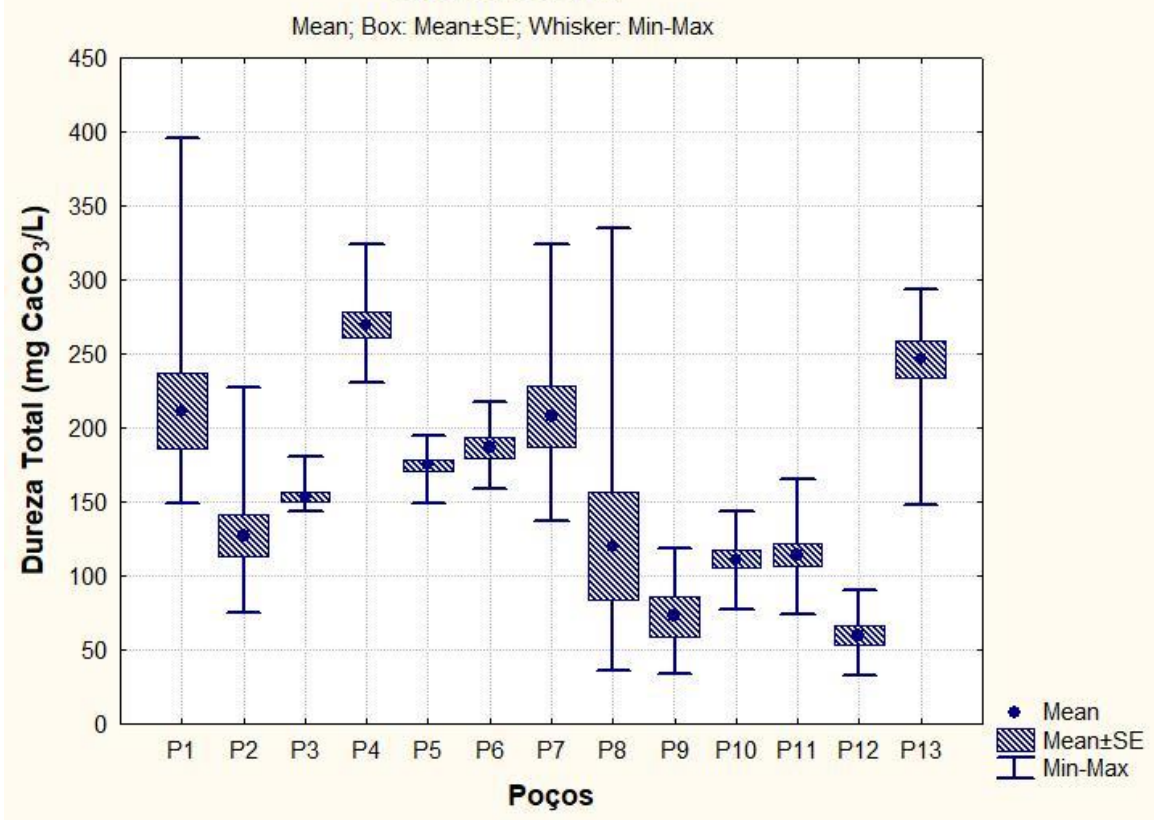

Figura 8 - Boxplot para valores de Cálcio ( $\mathrm{mg} / \mathrm{L})$

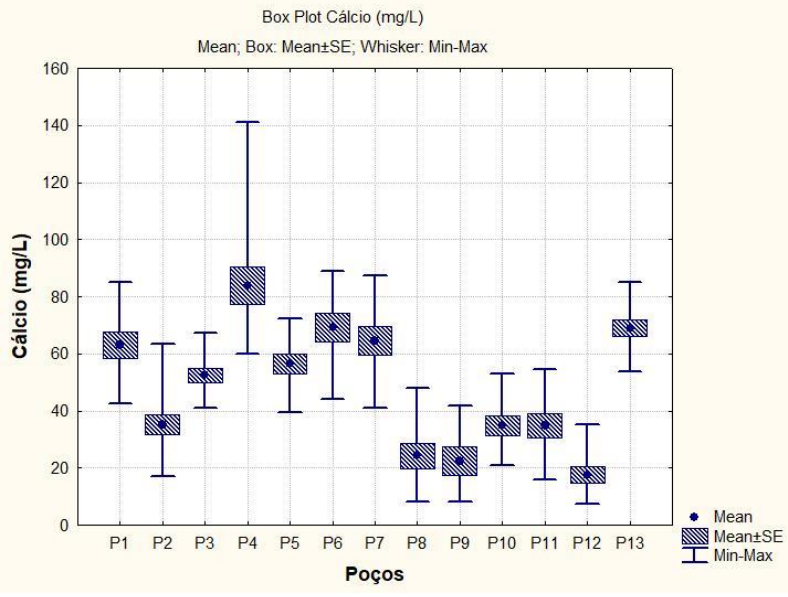

Chama a atenção a elevada concentração de íons cloretos em praticamente todos os poços durante o período em que foram avaliados. A grande maioria dos poços apresentou teores de $\mathrm{Cl}^{-}$acima do limite máximo permissível pela legislação, que é de $250 \mathrm{mg} / \mathrm{L}$, con-

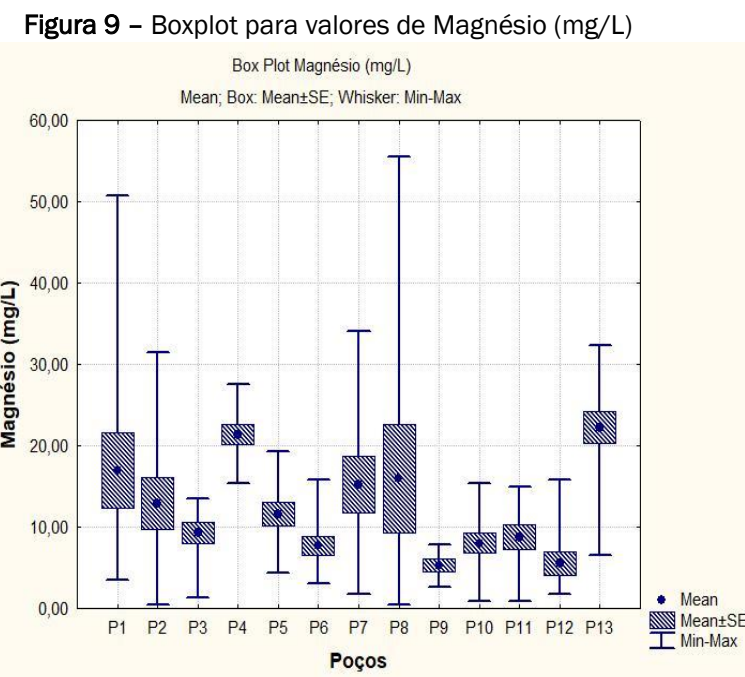

forme mostra a Figura 10. Elevados valores de concentração cloretos acarretam a rejeição ao consumo da água em função do gosto ruim que este íon provoca. 
Figura 10 - Boxplot para valores de Cloretos (mg /L)

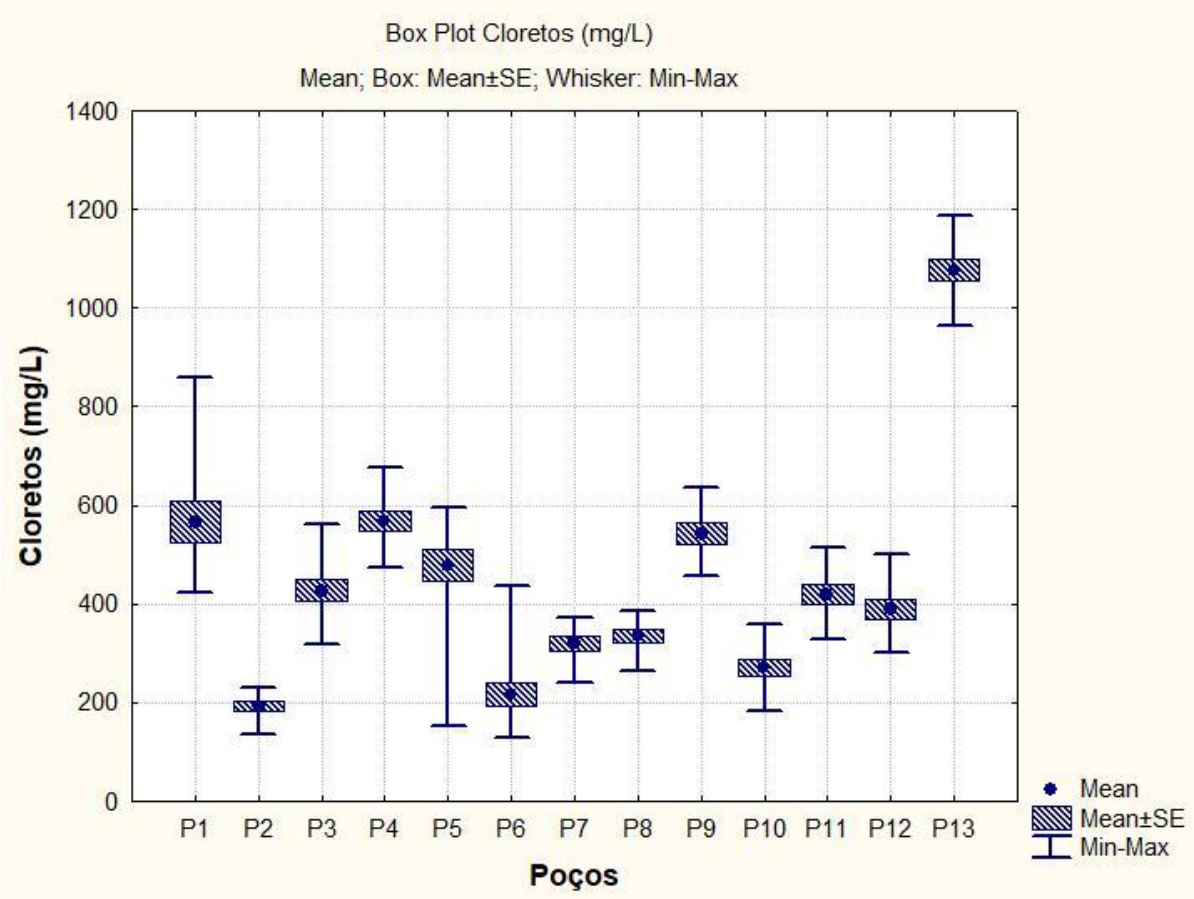

Outro íon presente em concentrações muito elevadas é o $\mathrm{Na}^{+}$, ficando acima de $200 \mathrm{mg} / \mathrm{L}$ em quase todos os poços, como é ilustrado pela Figura 11, chegando a atingir valores extremos acima de 1500 mg/L, como no caso do Poço 4, que se mostra o mais crítico com relação à concentração de íons. 0 padrão de potabilidade fixa em 200 mg/L o valor máximo permitido para a concentração de só-

dio em água para consumo humano, sob o risco de agregar gosto salgado à água com teores acima deste limite. Além disso, o consumo elevado de sódio está relacionado a problemas de saúde como hipertensão arterial, em virtude da propriedade que este íon possui de reter líquidos no corpo humano (WHO, 1978).

Figura 11 - Boxplot para valores de Sódio (mg/L) Box Plot Sódio

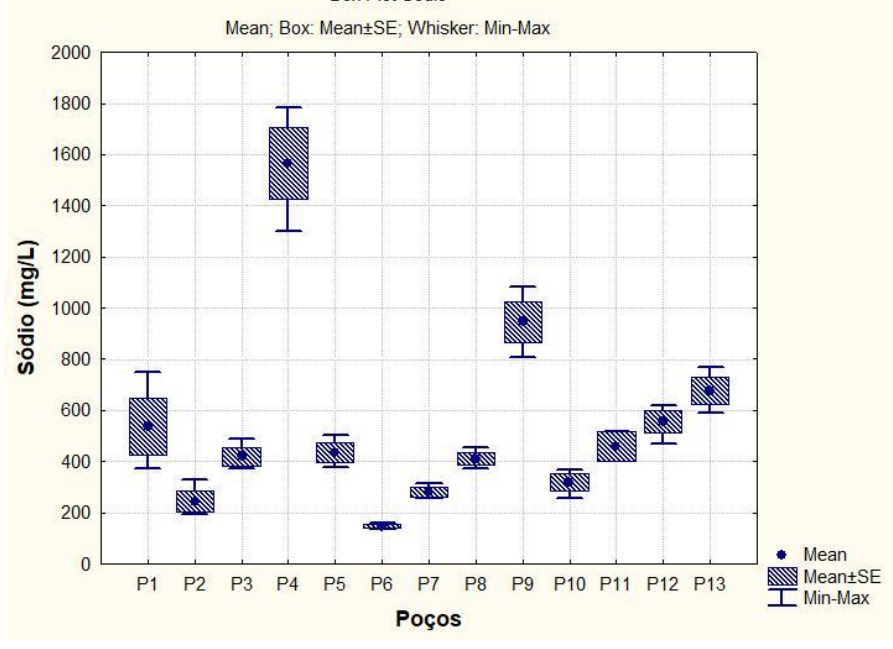

Figura 12 - Boxplot para valores de Potássio (mg/L)

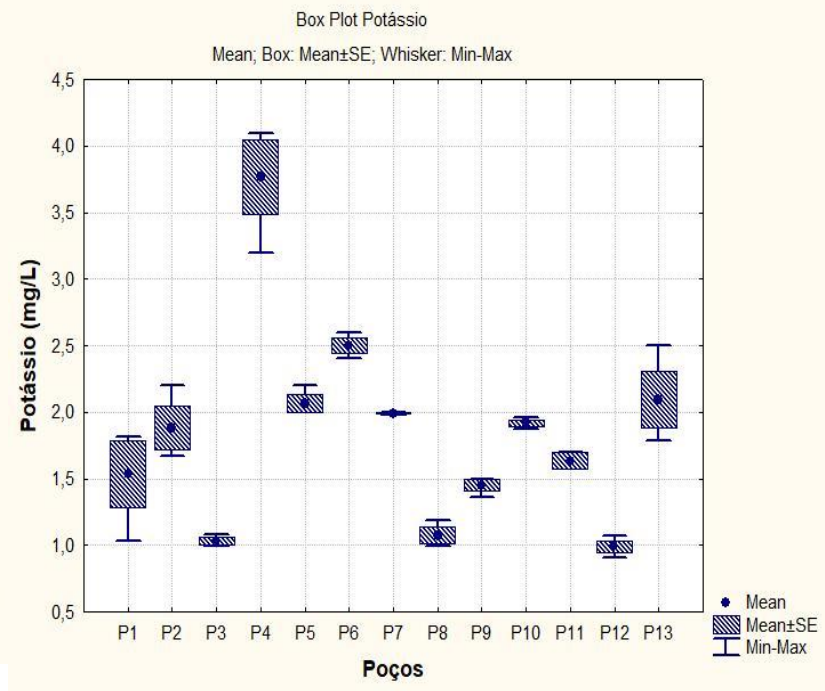


O íon $\mathrm{K}^{+}$, cujos resultados são mostrados na Figura 12, apresentou concentrações muito reduzidas em comparação ao sódio. Isso pode estar relacionado diretamente à composição do solo e da rocha nos quais a água está em contato. A legislação não estabelece limites para os teores deste íon. Corrêa et al., (2003), ao estudarem a mineralogia dos solos dessa região verificaram, por meio da difratometria de raios- $X$, que a fração silte dos horizontes superficiais e subsuperficiais desses solos revelou a presença de plagioclásio, feldspato e quartzo, além de picos de mica, clorita e anfibólio. Em todos estes solos, estes minerais são as principais fontes de $\mathrm{K}^{+}, \mathrm{Na}^{+}$ e $\mathrm{Ca}^{2+}$.

A capacidade de uma amostra de água em conduzir corrente elétrica (condutividade elétrica) está relacionada à concentração de

Figura 13 - Boxplot para valores de Condutividade Elétrica $(\mu \mathrm{S} / \mathrm{cm})$

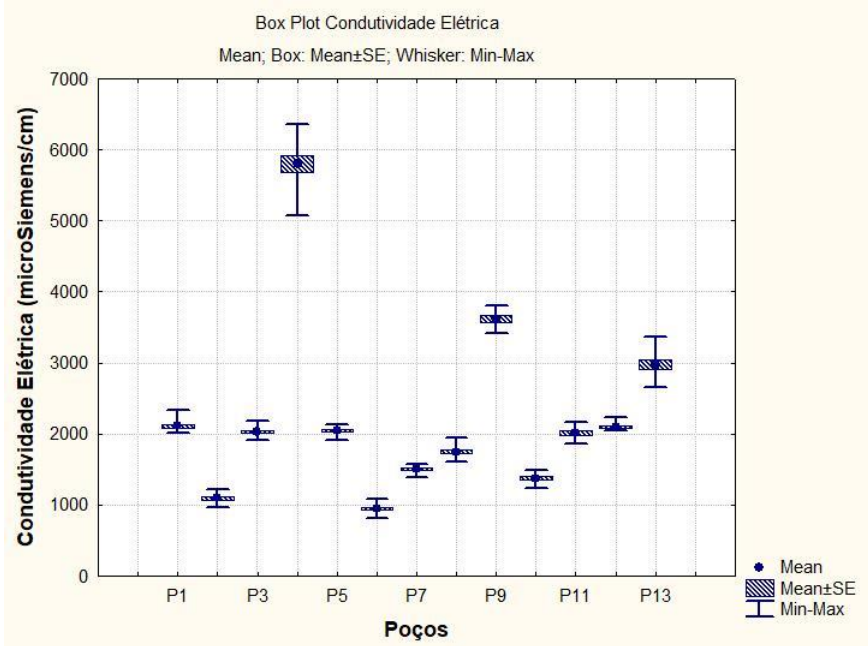

A partir da análise da Figura 15, pode-se concluir que os elevadores teores de STD estão intimamente correlacionados aos teores de sódio presente nas amostras, ou seja, o íon $\mathrm{Na}^{+}$é o principal responsável pela elevada salinidade desses poços, tendo em vista que, esses parâmetros apresentaram um coeficiente de correlação de 0,9833, o que significa uma alta correlação entre dois fatores.

A análise da qualidade e a classificação das águas dos poços quanto à salinidade foi feita pelo método Piper (1944). De acordo com Lordelo et al., (2018), o método Piper extrai de dois diagramas triangulares, os cátions principais $(\mathrm{Ca}+2, \mathrm{Mg}+2, \mathrm{Na}+\mathrm{e} \mathrm{K}+)$ e os ânions principais (HCO3-, CO32-, Cl-, SO4-2), que combinados geram informações que são dispostas em um losango situado entre íons (sais) presentes nessa solução (WHO, 1978). As Figuras 13 e 14, que mostram os resultados para condutividade elétrica e sólidos totais dissolvidos (STD), ilustram essa relação intrínseca entre esses dois parâmetros. A partir da análise dessas duas figuras, é possível verificar a elevada concentração de sais nesses poços. Tanto a Resolução CONAMA n ${ }^{\circ} 396$ de 2008, que dispõe sobre a classificação e diretrizes ambientais para o enquadramento das águas subterrâneas e dá outras providências, quanto a Portaria MS 2.914 de 2011, estabelecem o limite máximo de 1.000 mg/L para os teores de STD em águas subterrâneas para o consumo humano. Verifica-se que grande parte dos poços avaliados apresentam teores de STD superiores ao estabelecido pela legislação.

Figura 14 - Boxplot para valores de STD (mg/L)

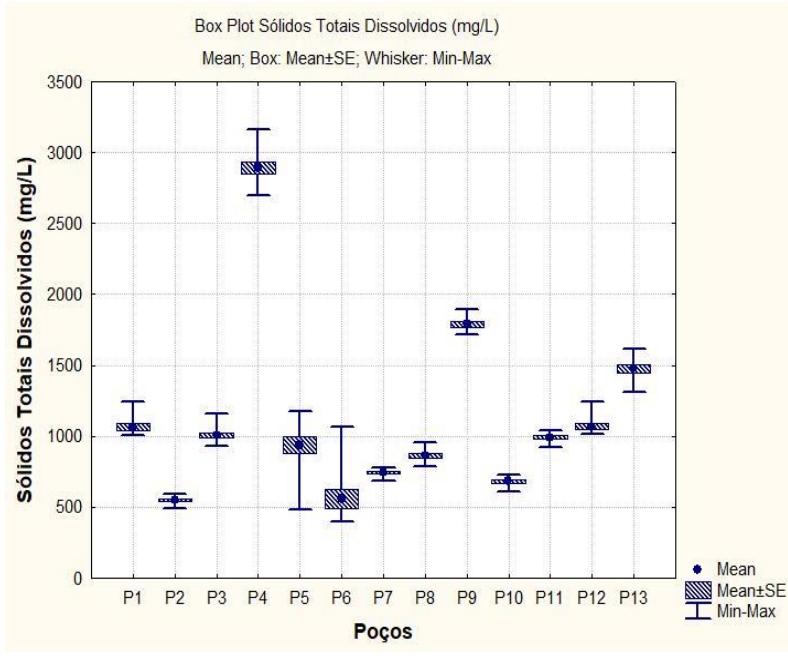

os mesmos. Os pontos iônicos ocupam espaços no lado direito do losango. Quanto mais para o lado direito do losango o ponto se localizar, mais salgada é a água em estudo.

A Figura 16 apresenta o Diagrama de Piper das amostras analisadas, obtido a partir do software livre Qualigraf, disponibilizado pela FUNCEME. De acordo com esse diagrama, verifica-se que os cátions predominantes são o $\mathrm{Na}+$, $\mathrm{Ca} 2+$ e $\mathrm{Mg} 2+$, e os ânions presentes em maior concentração são $\mathrm{Cl}$ - e HCO3-, o que pode ser corroborado pelos resultados apresentados anteriormente nos Boxplots. Isso permite classificar essas águas em dois tipos: sódico cloretadas (46\%) e sódico bicarbonatadas (54\%), conforme é apresentado na Tabela 2. 
Figura 15 - Correlação entre os parâmetros $\mathrm{Na}^{+}$x STD (mg/L)

Scatterplot (Correlações $210 v^{\star} 13 c$ )

STD $=230,4321+1,4146^{*} x ; 0,95$ Conf.Int.

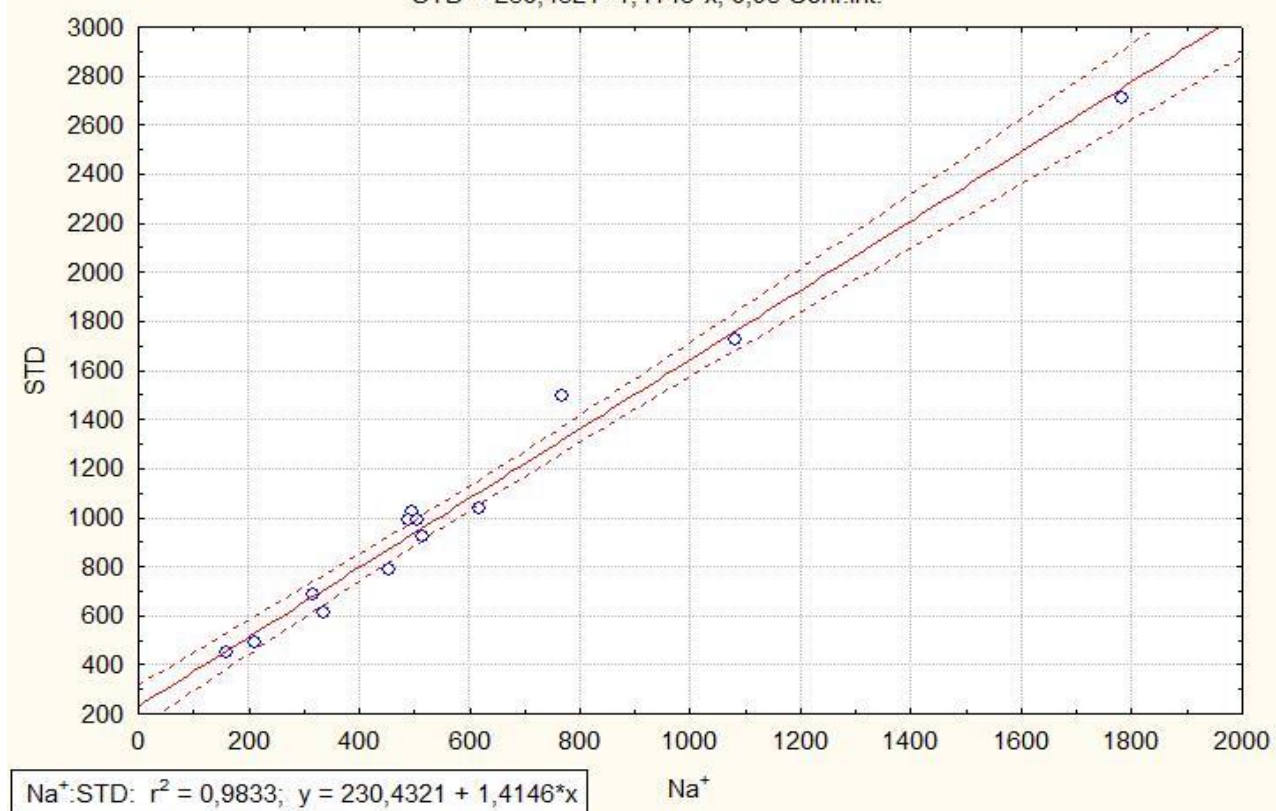

Figura 16 - Diagrama de Piper para os poços avaliados.

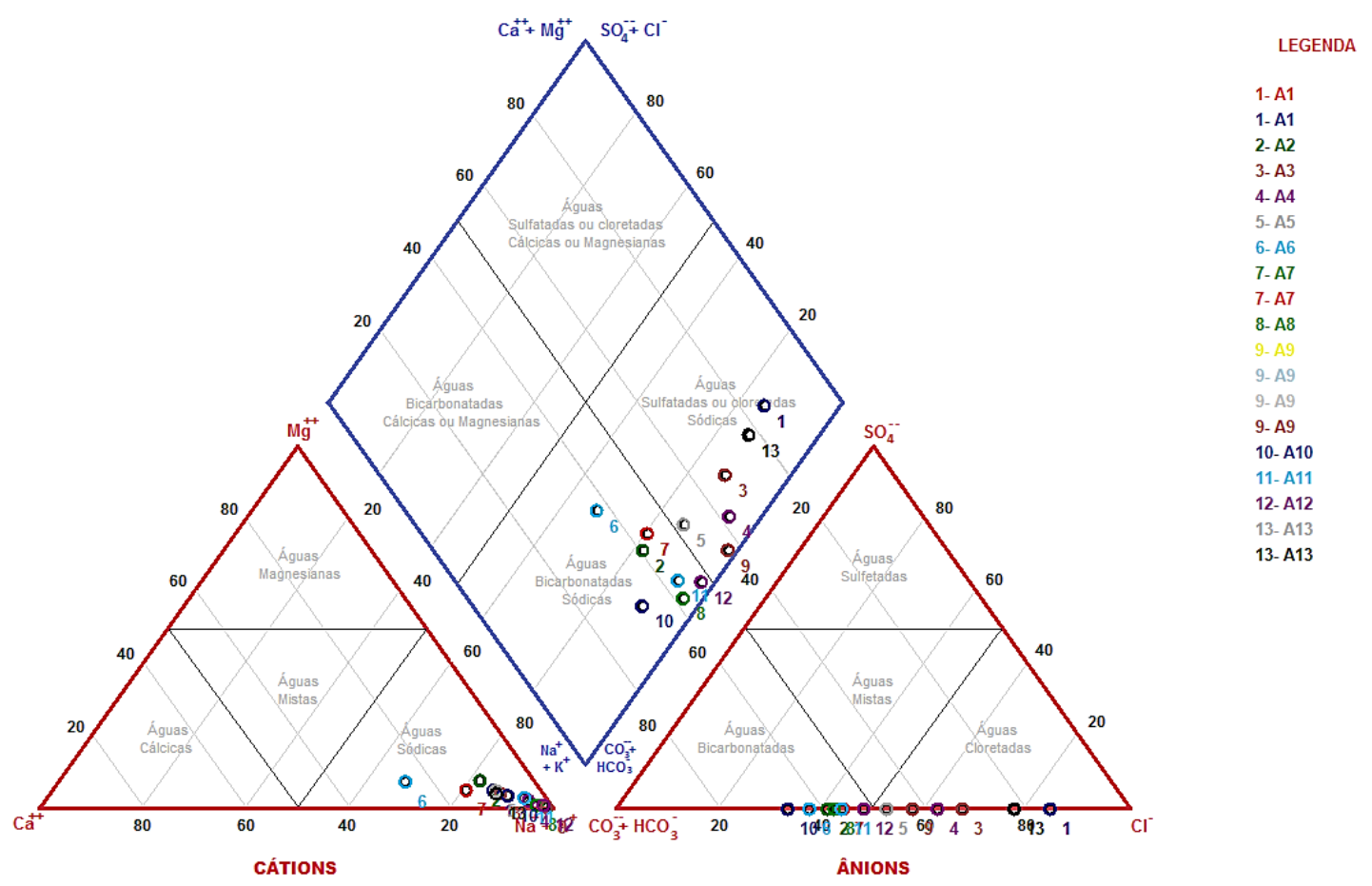


Tabela 2 - Classificação das águas quanto à hidroquímica e ao uso na irrigação

\begin{tabular}{ccc}
\hline Poço & Classificação Hidroquímica & Classificação para Irrigação \\
\hline Poço 01 & Sódica Cloretada & C3-S4 \\
Poço 02 & Sódica Bicarbonatada & C3-S2 \\
Poço 03 & Sódica Cloretada & C3-S4 \\
Poço 04 & Sódica Cloretada & C5-S4 \\
Poço 05 & Sódica Cloretada & C3-S4 \\
Poço 06 & Sódica Bicarbonatada & C3-S1 \\
Poço 07 & Sódica Bicarbonatada & C3-S3 \\
Poço 08 & Sódica Bicarbonatada & C3-S4 \\
Poço 09 & Sódica Cloretada & C4-S4 \\
Poço 10 & Sódica Bicarbonatada & C3-S3 \\
Poço 11 & Sódica Bicarbonatada & C3-S4 \\
Poço 12 & Sódica Bicarbonatada & C3-S4 \\
Poço 13 & Sódica Cloretada & C4-S4 \\
\hline
\end{tabular}

Os elevados teores de sais dissolvidos nessas amostras acarretam prejuízos não só para o consumo humano como também traz riscos para a agricultura, no caso de se utilizar essa água para a irrigação de culturas agrícolas.

Nesse contexto, a Figura 17 e a Tabela 2 apresentam o diagrama e a classificação das águas para fins de irrigação de acordo com o
Laboratório de Salinidade dos Estados Unidos (USSL), em que se pode verificar o risco de salinização do solo a partir do valor da condutividade elétrica, e o risco de sodificação, com base no valor da Razão de Adsorção de Sódio (RAS), obtido pela relação entre os íons $\mathrm{Na}^{+}, \mathrm{Ca}^{2+}$ e Mg${ }^{2+}$ (RICHARDS, 1954; AYERS E WESTCOT, 1976).

Figura 17 - Diagrama de classificação de água para irrigação (USSL)

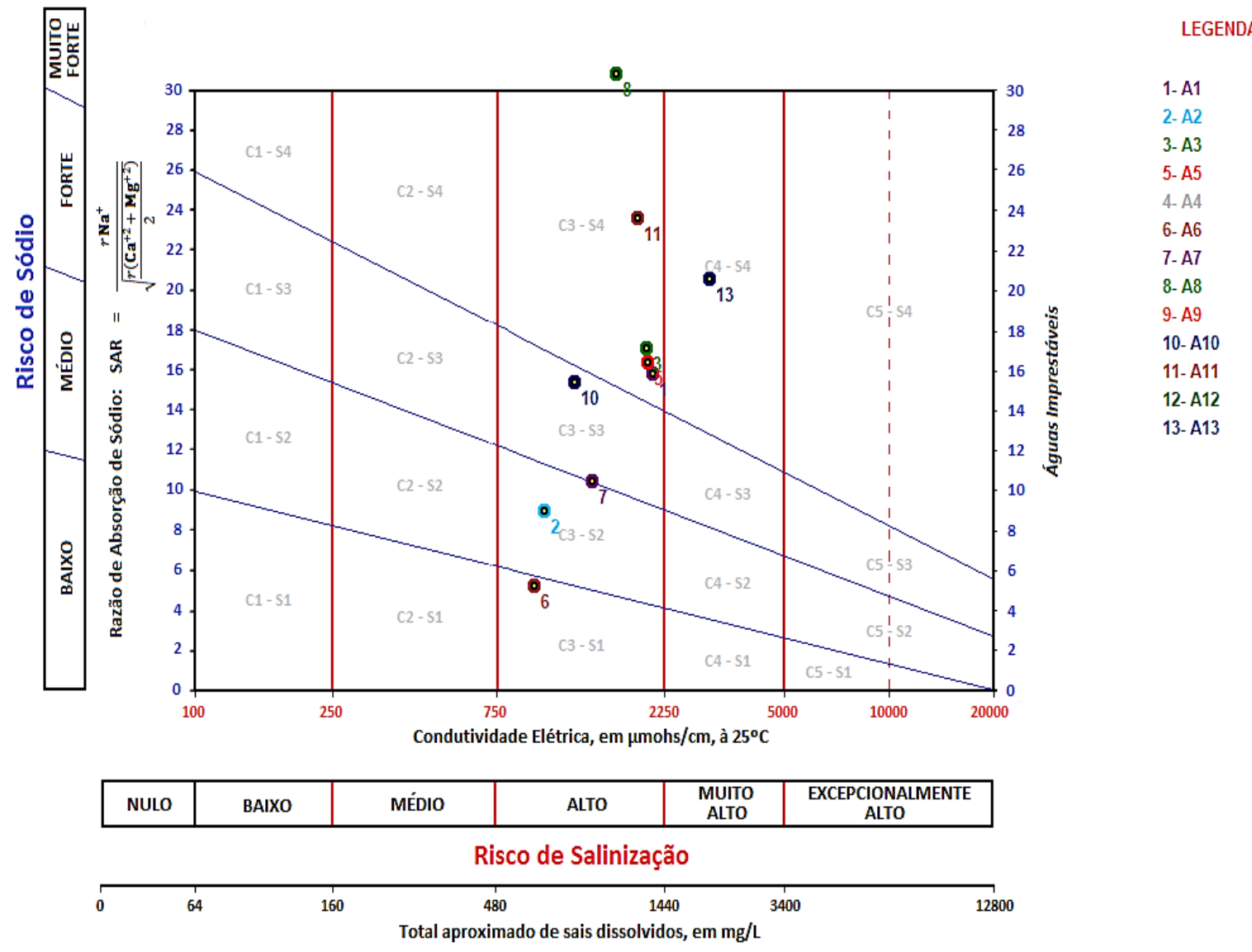


A partir do diagrama da Figura 17, obtido por meio do software Qualigraf, verificou-se que entre os poços avaliados $77 \%$ apresentaram risco alto de salinização, 15\% risco muito alto e $8 \%$ mostraram um risco excepcionalmente alto de salinização do solo. Alguns poços apresentaram valores tão elevados que nem aparecem no gráfico da Figura 17. Segundo Almeida (2010), águas com esse tipo de classificação (C3, C4 e C5) não são apropriadas para irrigação sob condições ordinárias, apenas em circunstâncias muito especiais. Nesse caso, os solos devem ser permeáveis, possuir drenagem adequada, alcançar boa lixiviação e ainda devem ser selecionadas culturas altamente tolerantes a sais.

Com relação ao risco de sodificação, 8\% dos poços amostrados apresentaram risco baixo, $8 \%$ indicaram risco médio, $15 \%$ risco forte e $69 \%$ apresentaram risco muito forte com relação à toxicidade do sódio. Com relação ao risco de sódio, de acordo com Almeida (2010), as águas classificadas em S3, S4 e S5 podem produzir níveis tóxicos de sódio trocável na maioria dos solos, sendo que estes necessitarão de práticas de manejo especiais, como boa drenagem, fácil lixiviação e aporte de matéria orgânica.

\section{CONCLUSÕES}

Diante dos resultados apresentados, é possível traçar um diagnóstico da qualidade hidroquímica das águas subterrâneas da zona urbana do município de Sousa/PB. Verificou-se que as águas dos poços avaliados apresentaram elevados teores de sólidos totais dissolvidos e, consequentemente, altos valores de condutividade elétrica, o que está associado à alta concentração de sais dissolvidos, sendo os íons predominantes $\mathrm{Na}^{+}, \mathrm{Cl}^{-}, \mathrm{HCO}_{3}{ }^{-}, \mathrm{Ca}^{2+} \mathrm{e} \mathrm{Mg}^{2+}$. Observouse que alguns parâmetros físico-químicos analisados ficaram fora dos limites estabelecidos pela legislação (sódio, alcalinidade, cloretos, STD) para a maioria dos poços, o que pode trazer riscos para a saúde das populações que consomem essas águas.

Com relação à classificação hidroquímica, verificou-se que $46 \%$ das amostras se enquadraram como sódico cloretadas e $54 \%$ sódico bicarbonatadas. No que diz respeito à classificação das águas para irrigação, para o risco de salinização, os poços foram classificados como tendo risco alto (C3), muito alto (C4) e excepcionalmente alto (C5). Já para o risco de sódio, as amostras apresentaram as classes de risco baixo - $\mathrm{S} 1(8 \%)$, risco médio - S2 (8\%), risco forte - S3 (15\%) e risco muito forte - S4 (69\%), o que mostra que o uso dessas águas na agricultura pode trazer sérios riscos ao solo, podendo torna-lo infértil em pouco tempo, sendo necessárias práticas de manejo especiais, como boa drenagem, fácil lixiviação e aporte de matéria orgânica

\section{REFERÊNCIAS}

ALMEIDA, O. A. Qualidade da água de irrigação. EMBRAPA Mandioca e Fruticultura. Cruz das Almas-BA. 2010.

AMERICAN PUBLIC HEALTH ASSOCIATION. Water Environment Federation. Standard methods for the examination of water and wastewater, 22 ed., 2012.

AYERS, R.S.; WESTCOT, D.W. Water quality for agriculture. Rome: FAO, 1976 97p. (FAO. Irrigation and Drainage Paper, 29).
BRASIL. Conselho Nacional do Meio Ambiente - CONAMA. Resolução $n^{\circ} 396$ de 03 de abril de 2008. Dispõe sobre a classificação e diretrizes ambientais para o enquadramento das águas subterrâneas. Brasília. DOU $n^{\circ} 66$, de 7 de abril de 2008.

BRASIL. Ministério da Saúde. Portaria $n .^{\circ} 2.914$, de 12 de Dezembro de 2011. Dispõe sobre normas de potabilidade de água para o consumo humano. Brasília: SVS, 2011. Oficial da União, 14 de dezembro de 2011.

CANADÁ. Guidelines for canadian drinking water quality: Guideline Technical Document - Hardness. 1979.

CIRILO, J. A. Políticas públicas de recursos hídricos para o semiárido brasileiro. Estudos Avançados, v. 22, n. 63, p. 61-82, 2008.

CLIMATE-DATA.ORG. Climatologia do município de Sousa-PB. Disponível em: https://pt.climate-data.org/location/42525/. Acesso em: 30/03/2018.

CORRÊA, M. M.; KER, J. C.; MENDONÇA, E. S.; RUIZ, H. A.; BASTOS, R. S. Atributos físicos, químicos e mineralógicos de solos da região das Várzeas de Sousa (PB). Revista Brasileira de Ciência do Solo, v. 27, n. 02. p. 311-324. 2003.

COSTA, C. L.; LIMA, R. F.; PAIXÃO, G. C.; PANTOJA, L., D., M. Avaliação da qualidade das águas subterrâneas em poços do Estado do Ceará, Brasil. Semana: Ciências Biológicas e da Saúde, Londrina, v. 33, n. 2, p. 171-180. 2012.

DEUSTCH, W. Groundwater geochemistry fundamentals and applications to contamination. USA: CRC, 1997.

IBGE - Instituto Brasileiro de Geografia e Estatística. Censo demográfico 2010. Disponível em: <http://www.censo2010.ibge.gov.br>.

LORDELO, L. M. K.; PORSANI, J. M.; BORJA, P. C. Qualidade físico-química da água para abastecimento humano em municípios do sertão da Bahia: um estudo considerando diversas fontes de suprimento. Revista águas subterrâneas, v. 32, n. 1, p. 97 - 105, 2018.

MOBUS, G., Software Qualigraf. Fundação Cearense de Meteorologia e Recursos Hídricos - FUNCEME, 2015.

PIPER, A.M. A graphic procedure in the geochemical interpretation of water analyses. Am. Geophysics Union Trans. v. 25, p. 914 - 923, 1944.

RICHARDS, L.A. Diagnosis and improvement of saline and alkali soils. Washington, D.C: United States Salinity Laboratory, 1954. 160p. (United States Department of Agriculture Handbook).

VON SPERLING, M. Introdução à qualidade das águas e ao tratamento de esgotos : princípios do tratamento biológico de águas residuárias. Belo Horizonte: DESA-UFMG, 2005.452 p. 452 p. v. 1.

WORLD HEALTHY ORGANIZATION - WHO. Sodium, chlorides and conductivity in drinking-water. Report on a WHO working group. Regional Office for Europe. 1978.

ZAVOUDAKIS, E.; COSTA, M.; SIQUEIRA, L.; ADDAD, J. E. Classificação hidroquímica e avaliação da salinidade da água freática em áreas do município de Vitória-ES. In: ENCONTRO NACIONAL DE PERFURADORES DE POÇOS , 15. SIMPÓSIO DE HIDROGEOLOGIA DO SUL-SUDESTE, 1., 2007.Anais... Gramado-RS. 2007. 